\title{
QUEBRA DE DORMÊNCIA DE SEMENTES DE CAPIM-NAVALHÃO
}

\author{
WuelissonJosé da SILVA* \\ Oscar Mitsuo YAMASHITA* \\ Paulo Cesar Laurindo SILVA* \\ Ricardo Adriano FELITO* \\ Adriano Maltezo da ROCHA* \\ Aureane Cristina Teixeira FERREIRA* \\ Marco Antonio Camillo de CARVALHO* \\ Tiago de Lisboa PARENTE** \\ Sheila CAIONI**
}

\begin{abstract}
*Faculdade de Ciências Biológicas e Agrárias. Programa de Pós Graduação em Biodiversidade e Agroecossistemas Amazônicos. Universidade do Estado de Mato Grosso (UNEMAT), Alta Floresta (MT), Brazil. E-mail: yama@unemat.br

**Faculdade de Engenharia de Ilha Solteira (FEIS). Universidade Estadual Paulista (UNESP), Ilha Solteira (SP), Brazil.
\end{abstract}

Recebido em: 30/08/2016 - Aprovado em: 12/12/2017 - Disponibilizado em: 30/12/2017

\section{RESUMO:}

As plantas daninhas, de forma geral, causam transtornos e prejuízos para diversos agricultores.O capim-navalhão (Paspalum virgatum) tem se destacado como uma agressiva planta daninha de pastagens em diversas regiões, especialmente em áreas de solo mais úmido. A sua baixa palatabilidade, grande produção de semente, tolerância a diferentes condições de estresse ambiental, e principalmente sua semelhança morfológica, fisiológica e bioquímica com as gramíneas forrageiras dificultam seu controle. O conhecimento da capacidade germinativa das sementes de plantas daninhas pode gerar subsídios para a adoção de práticas de manejo, visando reduzir sua população em ambiente agrícola ou de criações.O presente trabalho objetivou estudar os aspectos germinativos das sementes de capim-navalhão, visando avaliar a superação de dormência de suas sementes nos seguintes tratamentos: escarificação química utilizando ácido sulfúrico $\left(\mathrm{H}_{2} \mathrm{SO}_{4}\right)$, por 1, 5 e 15 minutos; embebição em água em temperatura ambiente por 2, 4, 8 e 16 horas; embebição em hipoclorito de sódio por 1, 5, 10 e 15 horas; e armazenamento em temperatura elevada $\left(40{ }^{\circ} \mathrm{C}\right)$ por $0,23,28,33$ e 38 dias. Assim, nas condições experimentais deste estudo, o uso de escarificação química proporcionou a maior percentagem e índice de velocidade germinativa de sementes de P. virgatum, assim como o método de armazenamento em temperatura elevada $\left(40{ }^{\circ} \mathrm{C}\right)$, especificamente por 23 e 33 dias.Temperaturas elevadas, tais como ocorrem no solo podem contribuir para a quebra de dormência das sementes capim-navalhão, assemelhando-se ao ato dos ruminantes ao se alimentarem das partes da gramínea, passando pelo trato digestivo,que possui efeito semelhante ao do ácido sulfúrico, contribuindo assim para que ocorra a quebra de dormência e,posteriormente disseminam as sementes da espécie.

Palavras chave: Paspalum virgatum.planta daninha.Germinação.temperatura elevada.hipoclorito de sódio. 


\title{
OVERCOME DORMANCY IN THE GERMINATION OF NAVALHÃO GRASS SEEDS
}

\begin{abstract}
Weeds, in general, cause inconvenience and loss for many farmers. The grassnavalhão (Paspalumvirgatum) has emerged as an aggressive weed of pastures in many regions, especially in wetter soil areas. Its low palatability, large seed production, tolerance to different conditions of environmental stress, and especially their morphological similarity, physiological and biochemical with grasses hamper their control. Knowledge of the germination of weed seeds can generate subsidies for the adoption of management practices to reduce the population in the agricultural environment or creations. This study investigated the germinal aspectsofnavalhãograssseeds, toevaluate the dormancy breaking of the seeds in the following treatments: chemical scarification using sulfuric acid $\left(\mathrm{H}_{2} \mathrm{SO}_{4}\right)$, for 1,5 and 15 minutes; immersion in room temperature water for 2, 4, 8 and 16 hours; immersion in sodium hypochlorite for 1, 5, 10 and 15 hours; and storage at elevated temperature $\left(40{ }^{\circ} \mathrm{C}\right)$ for $0,23,28,33$ and 38 days. Thus, under the experimental conditions of this study, the use of chemical scarification provided the highest germination percentage and speed index of P. switchgrass seeds, as well as the method of storage at elevated temperature $\left(40^{\circ} \mathrm{C}\right)$, specifically for 23 to 33 days. High temperatures, such as occur in the soil cancontributetobreakingdormancyofnavalhãograssseeds, resemblingthe act of ruminants by feeding the parts of the grass, through the digestive tract, which has effects similar to sulfuric acid, thus contributing to the occurrence of the dormancy breaking and then spread theseedsofthespecies.
\end{abstract}

Keywords: Paspalumvirgatum.weed.germination.elevatedtemperature.sodiumhypochlorite.

\section{INTRODUÇÃO}

A pecuária obteve grandes avanços econômicos, passando do quinto para o primeiro lugar no ranking dos maiores exportadores mundiais de carne bovina, correspondendo a um crescimento médio de 2,15 a $3,64 \%$ ao ano (IBGE, 2016). Apesar dessa evolução, diversos problemas ainda prejudicam a atividade. Dentre estes, a presença de plantas daninhas tem se tornado recorrente, especialmente quando estas ocorrem em conjunto com a degradação das pastagens. Essa adversidadeestá intimamente relacionada às características como: pastoreio intensivo com grande número de animais por área animal e o uso de poucas espécies forrageiras em grandes extensões. Essas condições agravam a degradação e infestação das plantas daninhas nas pastagens (ANDRADE et al., 2012).

As plantas daninhas são espécies rústicas capazes de sobreviver em diferentes condições ambientais, causando grandes prejuízos e, em alguns casos, até inviabilizar a atividade. Essas plantas causam reduções que podem atingir até $90 \%$ de perdas. $\mathrm{Na}$ pecuária, essas plantas interferem no desenvolvimento das pastagens, competindo por água, luz e nutrientes, além de reduzir a capacidade de lotação da cultura (CARVALHO, 2013).

$$
\text { As espécies daninhas }
$$

monocotiledôneas encontradas nas pastagens são as mais difíceis de serem controladas, pois suas características se assemelham às forrageiras de interesse, dificultando o seu controle.Outro limitante é a inexistência de produtos que sejam seletivos a essas espécies de plantas daninhas (DIAS FILHO, 2007).

$$
\text { Paspalumvirgatum, conhecido }
$$

também como capim-navalha ou capimnavalhão, é uma espécie de planta pertencente à família Poaceae. É uma planta daninha perene, herbácea, ereta, com porte de até 1,50 $\mathrm{m}$ de altura, apresenta um grande valor 
protéico, mas quando adulta, torna-se fibrosa e não palatável aos animais. Seu principal meio de reprodução é via sementes e através de rizomas. Seu florescimento ocorre entre os meses de outubro a maio, época de maior intensidade de chuvas, especialmente em regiões amazônicas. As plantas dessa espécie normalmente habitam ambientes úmidos, baixadas, beiras de córregos, rios, sendo também frequentemente encontradas nas pastagens (LORENZI, 2000).

Essa espécie apresenta dormência das sementes, uma estratégia comum em diversas plantas daninhas, que promove o escalonamento da germinação destas ao longo do tempo e do espaço, permitindo que estas possam ocupar as áreas, reduzindo a chance de serem dizimadas por algum evento climático ou de outra forma, mantendo seu banco de sementes no solo, sempre com elevada capacidade produtiva (ANDRADE et al., 2012).

Poucos estudos sobre a espécie são encontrados, especialmente aqueles que buscam o aprofundamento na compreensão sobre seu desenvolvimento em ambos os estágios (vegetativo e reprodutivo). Alguns estudos começaram a ser realizados somente depois de suas grandes infestações em pastagens degradadas pela síndrome da morte súbita no estado do Acre, entretanto estes realizaram seu manejo químico e cultural em áreas de grandes infestações (ANDRADE et al., 2012). Mas o conhecimento de informações sobre a capacidade germinativa da espécie podem fornecer subsídios para o desenvolvimento de práticas, em conjunto com outras técnicas, que venham a controlar e/ou manejar a espécie, mantendo-a em níveis inferiores aos de dano econômico.

O conhecimento sobre as condições ambientais mais adequadas para a quebra de dormência e consequentemente a germinação das sementes de uma espécie daninha pode possibilitar a previsão de dispersão e ocupação de regiões que seriam potencialmente colonizadas, bem como a época do ano com maior probabilidade de estabelecimento destas (SILVA et al., 2009b).

Neste sentido, o presente trabalho objetivou estudar a capacidade germinativa do capim-navalhão ( $P$. virgatum), em função de diferentes tratamentos de quebra de dormência de suas sementes. Com base nos resultados obtidos, é possível verificar como essa planta daninha pode germinar em situação a campo, podendo realizar práticas de manejo para reduzir a sua população.

\section{MATERIAL E MÉTODOS}

O experimento foi conduzido nas dependências do Laboratório de Tecnologia de Sementes e Matologia(LaSeM) da Universidade do Estado do Mato Grosso (UNEMAT), Campus Universitário de Alta Floresta - MT. 
Panículas de $P$. virgatum contendo espiguetas fisiologicamente maduras foram coletadas em áreas de infestação natural em piquetes de criação extensiva de bovinos na Fazenda Beira Rio, no município de Nova Monte Verde- MT, localizada nas coordenadas de $57^{\circ} 32^{\prime} 07^{\prime \prime}$ de longitude Oeste e 0958'24" de latitude Sul. Após a coleta, as sementes foram retiradas manualmente das panículas e armazenadas durante um período de sete dias em sacos de papelkraft em ambiente fresco e sombreado, sendo revolvidas uma vez ao dia. Após secagem natural, as estruturas foram submetidas à um processo de seleção visual, sendo descartadas aquelas aparentemente danificadas ou mal formadas.

$\mathrm{O}$ bioensaio foi realizado em delineamento inteiramente casualizado, com quatro repetições. Os tratamentos utilizados foram:

Escarificação Química (EQ), sendo utilizado ácido sulfúrico $\left(\mathrm{H}_{2} \mathrm{SO}_{4}\right.$ P.A. $)$ : as sementes ficaram expostas ao produto por 1 , 5, 10 e 15 minutos;

Embebição em Água em Temperatura Ambiente (ETA) por 2, 4, 8 e 16 horas;

Embebição em Hipoclorito de Sódio (EAS) por 1, 5, 10 e 15 horas;e

Armazenamento em temperatura elevada (AQ), $\left(40{ }^{\circ} \mathrm{C}\right)$ por $23,28,33$ e 38 dias.

As unidades experimentais foram representadas por caixas de acrílico transparente tipo gerbox $(11,0 \times 11,0 \times 3,5$ $\mathrm{cm}$ ), que foram forradas com 2 folhas de papéis germitest, previamente autoclavadas à $120^{\circ} \mathrm{C}$ por uma hora, e umedecidas diretamente com volume de água na quantidade de 2,5 vezes o peso dos papéis (BRASIL, 2009). Em cada caixa, foram colocadas 25 sementes (após respectivos tratamentos de quebra de dormência), as quais permaneceram em câmara de germinação tipo BOD, com temperatura de $25{ }^{\circ} \mathrm{C}$, e foto período de 12 horas de luz, por 15 dias.

A avaliação iniciou-se no primeiro dia após a montagem do experimento, prolongando-se até o décimo quinto dia, sendo verificado o número de sementes germinadas. Ao fim das avaliações determinou-se o Índice de Velocidade de Germinação (IVG), e percentual total de germinação. Além disso,foideterminadoo comprimento aéreo da plântula e da principalradícula formada, também foi determinada a massa seca das plântulas, conforme descrito a seguir.

Porcentagem de germinação (G) Considerou-se como critério para a germinação a emissão de raiz primária com comprimento igual ou superior a 2,0 mm (REHMAN et al., 1996). Os cálculos foram realizados de acordo com (LABOURIAU, 1983), segundo a fórmula abaixo:

$$
G(\%)=\left(\frac{N}{A}\right) X 100
$$


onde: $\mathrm{N}=$ Número de sementes germinadas; $\mathrm{A}=$ número total de sementes colocadas para germinar.

Índice de velocidade de germinação (IVG) - Foi realizado em conjunto com o teste de germinação, o IVG para cada subamostra foi obtido segundo a fórmula proposta por (MAGUIRE, 1962), apresentada a seguir:

$$
I V G=\frac{N_{1}}{D_{1}}+\frac{N_{2}}{D_{2}}+\ldots \ldots+\frac{N_{n}}{D_{n}}
$$

onde: $\mathrm{N}_{1}: \mathrm{n}=$ número de plântulas germinadas no dia $1, \ldots ., \mathrm{n} ; \mathrm{D}_{1}: \mathrm{n}=$ dias para ocorrência da germinação.

Comprimento de parte aérea e raiz principal das plântulas - Foram avaliadas dez plântulas de cada repetição, coletadas aleatoriamente, utilizando-se umpaquímetrodigital. Os comprimentos da parte aérea e raiz das plântulas para cada amostra, foram calculados dividindo-se o total das medidas pelo número de plântulas avaliadas, obtendo-se valores médios.

Massa seca de plântula - Definida como a massa média, expressa em gramas, correspondente à massa de dez plântulas por repetição, coletadas aleatoriamente, utilizando para secagem estufa com circulação de ar, regulada para $65 \pm 3{ }^{\circ} \mathrm{C}$ durante 48 horas, com pesagem em balança com precisão de $0,001 \mathrm{~g}$.

Os dados foram submetidos à análise de variância, comparando-se as médias pelo do teste de Scott-Knotta 5\% de probabilidade, através do programa de análises estatísticas Sisvar (FERREIRA, 2011).

\section{RESULTADOS}

Ocorreu significância em todos os tratamentos de quebra de dormência para todas as variáveis analisadas(Tabela 1).

Tabela 1. Quadro de análise de variância com quadrado médio do índice de velocidade de germinação (IVG), porcentagem de germinação (GER \%), comprimento da parte aérea (CPA), comprimento de raiz (CRA) e peso da matéria seca (MS) de plântulas de Paspalumvirgatumsubmetidas a tratamentos de quebra de dormência de sementes.

\begin{tabular}{cccccc}
\hline FV & GER $(\%)$ & IVG & CPA $(\mathbf{c m})$ & CRA $(\mathbf{c m})$ & MS $(\mathbf{m g})$ \\
\hline Tratamento & $33,21^{*}$ & $1,53^{*}$ & $10,01^{*}$ & $1,06^{*}$ & $0,001026^{*}$ \\
Erro & 0,76 & 0,02 & 0,07 & 0,02 & 0,000085 \\
\hline CV $(\%)$ & 20,68 & 11,31 & 14,81 & 9,93 & 33,06
\end{tabular}

*, significativo a 5\% de probabilidade pelo teste de Scott-Knott.

Valores transformados em $\sqrt{ } \mathrm{x}+1$

As sementes de $P$. virgatum temperatura elevada(AQ) por 23 e 33 dias, submetidas a tratamentos de quebra de apresentaram nesta ordem,as maiores dormência por escarificação química (EQ) em porcentagens de germinação, sendo superiores 5, 1 e 15 minutos e armazenamento em aos demais tratamentos (Tabela 2). 
O uso da escarificação química (EQ), independente do tempo promoveram os maiores IVG, seguidos dos tratamentos de armazenamento à quente (AQ) por 23 e 33 dias, que apresentaram resultados superiores à testemunha. Osvalores de IVG nos tratamentos de AQ por 28 e 38 dias e embebição em temperatura ambiente (ETA) por 1 hora, apresentaram valores semelhantesà testemunha. Para os demais tratamentos, obtiveram-se significativamente valores menores (Tabela 2).

Tabela 2. Porcentagem de germinação (G) e Índice de velocidade de germinação (IVG) de sementes de Paspalumvirgatum.

\begin{tabular}{lcc}
\hline Tratamentos & Germinação & IVG \\
\hline Testemunha & $30.0 \mathrm{~b}$ & $1.7 \mathrm{c}$ \\
E.Q. $1 \mathrm{~min}$ & $71.0 \mathrm{a}$ & $4.7 \mathrm{a}$ \\
E.Q. $5 \mathrm{~min}$ & $73.0 \mathrm{a}$ & $4.8 \mathrm{a}$ \\
E.Q. $15 \mathrm{~min}$ & $63.0 \mathrm{a}$ & $4.4 \mathrm{a}$ \\
A.Q. $23 \mathrm{ds}$ & $57.0 \mathrm{a}$ & $3.7 \mathrm{~b}$ \\
A.Q. $28 \mathrm{ds}$ & $25.0 \mathrm{~b}$ & $1.6 \mathrm{c}$ \\
A.Q. $33 \mathrm{ds}$ & $51.0 \mathrm{a}$ & $3.0 \mathrm{~b}$ \\
A.Q. $38 \mathrm{ds}$ & $9.0 \mathrm{c}$ & $0.6 \mathrm{c}$ \\
E.A.S. $1 \mathrm{hs}$ & $12.0 \mathrm{c}$ & $0.7 \mathrm{c}$ \\
E.A.S. $5 \mathrm{hs}$ & $4.0 \mathrm{~d}$ & $0.2 \mathrm{~d}$ \\
E.A.S. $10 \mathrm{hs}$ & $2.0 \mathrm{~d}$ & $0.2 \mathrm{~d}$ \\
E.A.S. $15 \mathrm{hs}$ & $1.0 \mathrm{~d}$ & $0.0 \mathrm{~d}$ \\
E.T.A. $2 \mathrm{hs}$ & $0.0 \mathrm{~d}$ & $0.0 \mathrm{~d}$ \\
E.T.A. $4 \mathrm{hs}$ & $4.0 \mathrm{~d}$ & $0.1 \mathrm{~d}$ \\
E.T.A. $8 \mathrm{hs}$ & $3.0 \mathrm{~d}$ & $0.1 \mathrm{~d}$ \\
E.T.A. $16 \mathrm{hs}$ & $6.0 \mathrm{c}$ & $0.2 \mathrm{~d}$
\end{tabular}

Médias seguidas de mesma letra na coluna não diferem estatisticamente entre si pelo teste de Scott-Knotta 5\% de probabilidade.

E.Q: escarificação química; A.Q: armazenamento a quente. E.A.S: embebição em hipoclorito de sódio; E.T.A: embebição em água a temperatura ambiente.

Os tratamentos que apresentaram os melhores resultados de comprimento de parte aérea (CPA) foram os de AQ por 38 e 23 dias respectivamente, seguidos pela testemunha e AQ por 33 e 28 dias, não ocorrendo diferença significativa entre estes.Após esses tratamentos, o uso de EQ por 15,5 e 1 minutos obtiveram os maiores valores, seguidos por hipoclorito de sódio (EAS) por 1h, os demais tratamentos foram inferiores (Tabela 3). 
A testemunha, EQ por 15 minutos, AQ por 23 e 38 dias, EQ por 5 minutos, AQ por 33 dias, EQ por 1 minuto e AQ por 28 dias, respectivamente, apresentaram os maiores resultados de comprimento radicular, sem diferença significativa. Em sequência o tratamento EAS por $1 \mathrm{~h}$, foi inferior significativamente em relação aos citados, e os demais tratamentos que se apresentaram os com menor comprimento radicular (Tabela 3).
Para avaliação de peso de massa seca (MS), a testemunha obteve o maior resultado, seguida pelos tratamentos EQa 1 minuto, AQ por 28 dias, EQ por 15 e 5 minutos, AQ por 23 e 33 dias e EAS por 1 hora, respectivamente sem diferença significativa, seguidos pelos tratamentos ETA por 4 e 16 horas, AQ por 38 dias eEAS por 5 horas. Os demais tratamentos foram os que obtiveram menores médias (Tabela 3).

Tabela 3. Comprimento da parte aérea (CPA), comprimento radicular (CRA) e peso de massa seca de plântulas (MS), de sementes de Paspalumvirgatum.

\begin{tabular}{lccc}
\hline Tratamentos & CPA $(\mathbf{c m})$ & CRA $(\mathbf{c m})$ & MS $(\mathbf{g})$ \\
\hline Testemunha & $3.74 \mathrm{a}$ & $3.09 \mathrm{a}$ & $0.002875 \mathrm{a}$ \\
E.Q. 1min & $2.20 \mathrm{~b}$ & $2.74 \mathrm{a}$ & $0.001900 \mathrm{a}$ \\
E.Q. 5min & $2.26 \mathrm{~b}$ & $2.87 \mathrm{a}$ & $0.001700 \mathrm{a}$ \\
E.Q. 15min & $2.38 \mathrm{~b}$ & $3.01 \mathrm{a}$ & $0.001750 \mathrm{a}$ \\
A.Q. 23ds & $3.75 \mathrm{a}$ & $2.97 \mathrm{a}$ & $0.001625 \mathrm{a}$ \\
A.Q. 28ds & $3.56 \mathrm{a}$ & $2.67 \mathrm{a}$ & $0.001775 \mathrm{a}$ \\
A.Q. 33ds & $3.68 \mathrm{a}$ & $2.76 \mathrm{a}$ & $0.001425 \mathrm{a}$ \\
A.Q. 38ds & $3.83 \mathrm{a}$ & $2.96 \mathrm{a}$ & $0.000550 \mathrm{~b}$ \\
E.A.S. 1hs & $1.18 \mathrm{c}$ & $1.02 \mathrm{~b}$ & $0.001350 \mathrm{a}$ \\
E.A.S. 5hs & $0.27 \mathrm{~d}$ & $0.33 \mathrm{c}$ & $0.000550 \mathrm{~b}$ \\
E.A.S. 10hs & $0.22 \mathrm{~d}$ & $0.06 \mathrm{c}$ & $0.000175 \mathrm{c}$ \\
E.A.S. 15hs & $0.11 \mathrm{~d}$ & $0.08 \mathrm{c}$ & $0.000275 \mathrm{c}$ \\
E.T.A. 2hs & $0.00 \mathrm{~d}$ & $0.00 \mathrm{c}$ & $0.000000 \mathrm{c}$ \\
E.T.A. 4hs & $0.12 \mathrm{~d}$ & $0.21 \mathrm{c}$ & $0.000400 \mathrm{~b}$ \\
E.T.A. 8hs & $0.20 \mathrm{~d}$ & $0.12 \mathrm{c}$ & $0.000225 \mathrm{c}$ \\
E.T.A. 16hs & $0.43 \mathrm{~d}$ & $0.40 \mathrm{c}$ & $0.000725 \mathrm{~b}$
\end{tabular}

Médias seguidas de mesma letra na coluna não diferem estatisticamente entre si pelo teste de Scott-knott a 5\% de probabilidade.

E.Q: escarificação química; A.Q: armazenamento a quente. E.A.S: embebição em hipoclorito de sódio; E.T.A: embebição em água a temperatura ambiente. 


\section{DISCUSSÃO}

Os maiores percentuais de germinação foram obtidos quando da utilização de ácido sulfúrico. Este ácido promove o desgaste do tegumento das sementes, favorecendo a difusão de oxigênio e a entrada de água através das glumas, proporcionando o reinício do processo germinativo (CARVALHO e NAKAGAWA, 2000). Entretanto, vale ressaltar que a eficiência do uso de ácido vai depender do tempo de imersão das sementes e de outras características próprias de cada espécie, como espessura e composição química das células dos tecidos de revestimento das sementes (YAMASHITA e ALBERGUINI, 2011), podendo, se mantidas em tempo excessivo em ácido, reduzir a germinação dessa espécie, além de influenciar negativamente no IVG destas.

$$
\text { Carvalho e Carvalho }
$$
realizaram escarificação em ácido sulfúrico em sementes de P.notatum e relataram ação benéfica na germinação por 7 e 15 minutos. Oliveira et al. (2003), também utilizaram esse tratamento para quebra de dormência em sementes de Peltophorumdubium, e observaram resultados favoráveis em embebição por 15 minutos.

Ainda, Siqueira-Silva et al. (2009) observaram aumento na germinação quando sementes de Adenanthera pavonina foram mantidas em embebição em ácido sulfúrico até 20 minutos. Goulart et al. (2011) em experimento com sementes de Colubrina glandulosa com uso de escarificação química por $30,60,90,120$ e 150 minutos também observaram aumento na germinação. Por outro lado, Toledo et al. (1995), em estudos realizados com sementes de diferentes espécies do gênero Panicum, não obtiveram resultados significativos na germinação quando submetidas a escarificação com ácido sulfúrico, sendo que todas sementes foram mortas. Silva et al. (2009a), ao realizarem escarificação com ácido sulfúrico concentrado por $1,2,4,8,16$ e 32 minutos, em sementes de Rottboelliacochinchinensis também observaram $0 \%$ de germinação.

Os resultados encontrados no presente trabalho demonstraram a eficiência no uso desse método para superação de dormência para $P$. virgatum. Em situação a campo, uma ação ecológica que se assemelha à escarificação química de sementes é o ato dos animais se alimentarem das folhasjunto com as sementes, passando pelo estômago onde ficam em contato com o ácido estomacal. Este ácido age de maneira similarao ácido sulfúrico, estudado no presente trabalho. Depois, os animais defecam e disseminam a espécie, suja semente suportou a ação corrosiva do tegumento das sementes, realizando a quebra da dormência destas.

O uso de temperatura elevada na superação de dormência de sementes $P$. virgatum atingiu valores elevados, se comparada a outros tratamentos, mas inferior 
à escarificação química, sendo semelhante a diversos outros trabalhos. Kissmannet al. (2008) utilizaram armazenamento a quente por 20,25 e $30{ }^{\circ} \mathrm{C}$ por diferentes dias, na quebra de dormência de sementes de A.pavoninae obtiveram percentuais elevados mas nunca superiores aos verificados no uso de escarificação química. Já Giachiniet al. (2010), em trabalho na superação de dormência em sementes de Samanea tubulosa, não obtiveram resultados significativos na germinação, quando foram submetidas aos tratamentos de armazenamento a quente por 20, 25, 30 e 35 ${ }^{\circ} \mathrm{C}$ por diferentes tempos, comparados a outros tratamentos. Dutra et al. (2007) também não observaram resultados significativos na superação de dormência de sementes de Senna siamea,quando submetidas ao armazenamento a calor e umidade por $40 \mathrm{a}$ $45^{\circ} \mathrm{C}$.

A temperatura pode afetar as reações bioquímicas que determinam todo o processo germinativo e que cada espécie depende de limites de temperatura em mínimo, ótimo e máximo (NASSIF et al., 1998). A velocidade de germinação e uniformidade de emergência diminuem com temperaturas abaixo da ótima e temperaturas acima da ótima aumentam a velocidade de germinação, embora somente as sementes mais vigorosas possam germinar.

As temperaturas elevadas à que assementes de $P$. virgatum foram submetidas tentaram simular o que ocorre nas situações de campo, visto que, nos ambientes de dispersão desta espécie, após a plena maturação, as sementes são dispersas e caem sobre o solo, palhada ou outra superfície, propensas a condições de insolação e elevada temperatura, especialmente durante a época de seca, que se antecede ao período chuvoso em regiões do Centro-Oeste e Norte do Brasil. Assim, verificou-se que a espécie pode sofrer quebra de dormência das sementes simplesmente pela ação da temperatura elevada que ocorre naturalmente em seu ambiente de dispersão. Esta característica ecológica é muito importante para sua capacidade de ocupação de áreas, dependendo apenas do efeito natural do ambiente (PARREIRA et al., 2011).

Dessa maneira, a agressividade e perpetuação desta espécie podem ser muito maiores, evidenciadas por diferentes fatores como elevada produção de sementes que apresentam algum mecanismo de dormência para sobrevivênciaem condições adversas impostas pelo ambiente (VIVIAN et al., 2008). Além disso, as sementes das plantas daninhas que estão dormentes não sãoafetadas pela maioria dos métodos de controle, enquanto que, as que estão em processo de germinação, tornam-se muito vulneráveis (DIAS FILHO et al., 1996).

O uso de hipoclorito de sódio na quebra de dormência, não promoveu elevação na porcentagem de germinação das sementes, se comparados ao todos os tratamentos EQ e 
AQ. Estes resultados diferem dos relatados por Garcia et al. (2000), em experimentos na superação de dormência de sementes de Piper nigrumem que o uso de hipoclorito de sódio a $20 \%$ por 5 minutos promoveu um importante acréscimo na germinação (60\%), mas não significativo se comparado a outros tratamentos, pois o uso desse produto fez com que ocorresse a remoção da mucilagem que envolve as sementes. Assim também, Dias \&Shioga (1997), estudando a quebra de dormência deOryza sativa com uso de hipoclorito de sódio a $1 \%$ por 24 horas, verificaram os melhores resultados na germinação das sementes.

A baixa porcentagem de germinação encontrada no presente trabalho, quando as sementes foram submetidas a este tratamento, pode estarrelacionada ao efeito que o hipoclorito causou nas sementes. O uso de hipoclorito de sódio pode interferir na qualidade fisiológica das sementes, induzindo-as a dormência, dependendo da concentração e do tempo de exposição a esse produto (Borges et al., 1993). Menezes et al. (2009), afirmam que paraO. sativa, o uso de hipoclorito de sódio reduz a germinação e faz com que esse produto cause a redução na absorção de água e o aumento do comprimento radicular das plântulas.

Os tratamentos de embebição obtiveram médias inferiores às da escarificação química e armazenamento a quente, mas superaram a porcentagem de germinação verificada na testemunha. Eira et al. (1993) também não obtiveram valoreselevados em tratamentos a embebição em temperatura ambiente por $24 \mathrm{~h}, 48 \mathrm{~h}$ e $72 \mathrm{~h}$ na quebra de dormência de sementes de Enterolobium contortisiliquum. Alves et al. (2004) verificaram dados semelhantes, ou seja, baixa porcentagem de germinação quando sementes de Bauhinia divaricata foram submetidas à embebição em temperatura ambiente por $24 \mathrm{~h}$.

A água é o fator de maior influência sobre o processo de germinação.Com a absorção de água por embebição, ocorre a reidratação dos tecidos e consequentemente a intensificação da respiração e de todas as outras atividades metabólicas, resultando no fornecimento de energia e nutrientes necessários para a retomada de crescimento do eixo embrionário. Por outro lado, o excesso de umidade causa o impedimento à penetração do oxigênio, provocando o decréscimo de germinação (MARCOS FILHO, 2005). A baixa porcentagem de germinação que ocorreu nesse tratamento pode estar relacionada à impermeabilidade que as sementes de $P$. virgatum apresentam ou ao excesso de água, que pode ter impedido a entrada de oxigênio.

Para a variável CPA, observou-se que, apesar da EQ ter sido o tratamento que promoveu maior percentual de germinação, a agressividade corrosiva do ácido pode ter prejudicado parcialmente o desenvolvimento 
das plântulas, especialmente a parte aérea, que sofreu um decréscimo de até $40 \%$ no comprimento da parte aérea das plântulas. $\mathrm{O}$ mesmo efeito prejudicial pode ter ocorrido no tratamento com hipoclorito, evidenciando por uma redução de até $97 \%$ no comprimento radicular das plântulas.

Já o armazenamento a quente não foi um processo tão agressivo, permitindo que a formação da parte aérea não sofresse redução significativa.

A embebição das sementes em água por longo tempo pode ter provocado a morte do embrião e os que puderam se desenvolver, foram prejudicados, tendo sua plântula alcançando valores muitos baixosnesta mesma variável. A falta de oxigênio por longos períodos pode ser um fator extremamente prejudicial ao desenvolvimento inicial de uma plântula, mesmo que esta seja adaptada a condições de solo úmido.

Para CRA, observou-se que tanto EAS como ETA por tempo prolongado prejudicaram o desenvolvimento do sistema radicular. De maneira similar ao que foi observado na parte aérea, as raízes de P.virgatum, também foram afetadas pelo tratamento com hipoclorito.

Assim, é possível relacionar o acúmulo de parte aérea e radicular na massa seca final, permitindo inferir sobre o efeito prejudicial de hipoclorito de sódio na formação de plântula. Além disso, verifica-se que os valores de MS na embebição das sementes foram significativamente baixos, demonstrando uma sensibilidade da espécie a condições de encharcamento por tempo prolongado, divergindo da literatura que afirma sobre a capacidade da espécie em se adaptar a condições de presença de água em abundância (ANDRADE et al., 2012). Possivelmente essa capacidade se limita a plantas já estabelecidas, mas não se estende às sementes produzidas por estas que ficam expostas as condições de encharcamento após a sua dispersão.

\section{CONCLUSÃO}

Nas condições experimentais deste estudo, a escarificação química proporcionou a maior germinabilidade e velocidade do processo nas sementes de Paspalum virgatum.

Temperaturas elevadas, tais como ocorrem no solo podem contribuir para a quebra de dormência das sementes de $P$. virgatum.

A embebição de sementes de $P$. virgatum em água na temperatura ambiente $\mathrm{e}$ em hipoclorito de sódio e por tempos prolongados prejudica a germinação e ocasiona a má formação de plântulas.

\section{REFERÊNCIAS BIBLIOGRÁFICAS}

ALVES, A.U.; DORNELAS, C.S.M,; BRUNO, R.L.A,; ANDRADE, L.A. ALVES, D.U. Superação da dormência em sementes de Bauhiniadivaricata L. Acta Botânica 
Brasílica, São Paulo, v.18, n.4, p.871-879, 2004.

ANDRADE, C.M.S.; FONTES, J.R.A.; OLIVEIRA, T.K.; FARINATI, L.H.E.

Reforma de pastagens com alta infestação de capim-navalha (Paspalumvirgatum). Circular Técnica, Embrapa Acre. 2012. Disponível em <https://www.embrapa.br/busca-depublicacoes/-/publicacao/946032/reforma-depastagens-com-alta-infestacao-de-capimnavalha-paspalum-virgatum>. Acesso em: 15 abr. 2016.

BRASIL. Ministério da Agricultura, Pecuária e Abastecimento. Regras para análise de sementes. Ministério da Agricultura, Pecuária e Abastecimento. Secretaria de Defesa Agropecuária. Brasília, DF: Mapa/ACS, 2009. $395 p$.

BORGES, E.E.L.; RENA, A.B. Germinação de sementes. Sementes Florestais Tropicais. Brasília: ABRATES, p.83-135, 1993.

CARVALHO, L.B. Plantas Daninhas. UDESC: Lages.82 p., 2013.

CARVALHO, R.I.N.; CARVALHO, D.B. Germinação de sementes de um ecótipo de paspalum da região de Guarapuava PR.Semina: Ciências Agrárias, Londrina, v. 30, suplemento 1, p. 1187-1194, 2009.

CARVALHO, N.; NAKAGAWA, J. Sementes: ciência, tecnologia e produção. 4.ed.

Jaboticabal: FUNEP, 2000. 588p.

DIAS FILHO, M.B.; MARTINS, B.A.B.; CHAMMA, H.M.C.P.; DIAS, C.T.S.; CHRISTOFFOLETI, P.J.

GerminationandemergenceofStarchytarphetaca yennensisandIpomoeaasarifolia. Planta

Daninha, v.14, n.2, p.118-123, 1996.

DIAS FILHO, M. B. Degradação de pastagens: processos, causas e estratégias de recuperação. - 3. ed. - Belém, PA: Embrapa Amazônia Oriental, 2007. 190p.

DIAS, M.C.L.L.; SHIOGA, P.S. Tratamentos para superar a dormência em sementes de arroz (Oryza sativa L.). Revista Brasileira de

Sementes, Londrina,v.19, n.1, p.52-57. 1997.
DUTRA, A.S.; MEDEIROS FILHO, S.; TEÓFILO, E.M.; DINIZ, F.O.; Germinação de sementes de Senna siamea (Lam.). Revista Brasileira de Sementes, Londrina, v. 29, n.1, p.160-164, 2007.

EIRA, M.T.S.; FREITAS, R.W.A.; MELLO, C.M.C. Superação da dormência de sementes de Enterolobiumcontortisiliquum (Vell.)

MorongLeguminosae. Revista Brasileira de Sementes, Londrina, v. 15, n. 2, p. 177-181, 1993.

FERREIRA, D.F. Sisvar: a computerstatisticalanalysis system. Ciência e Agrotecnologia, Lavras, v. 35, n.6, p. 10391042, 2011.

GARCIA, J.; KAMADA, T.; JACOBSON, T.K.B.; CURADO, M.A.; OLIVEIRA, S.M. Superação de dormência em sementes de pimenta-do-reino (Piper nigrumL.). Pesquisa Agropecuária Tropical, Goiânia, v.30, n.2, p. 51-54, 2000.

GIACHINI, R.M.; LOBO, F.A.; ALBUQUERQUE, M.C.F.; ORTÍZ, C.E.R. Influência da escarificação e da temperatura sobre a germinação de sementes de Samanea tubulosa (Benth.). Acta Amazônica,Manaus, v.40, n.1, p. 75- 80, 2010.

GOULART, P.H.S.B.; MONDO, V.H.V.; COELHO, A.D.J. Escarificação química para a superação da dormência de sementes de saguaraji-vermelho (Colubrina glandulosa). Revista Árvore, Viçosa, v.35, n.1, p.119-124, 2011.

IBGE. Instituto Brasileiro de Geografia e Estatística. Exportação brasileira de carne bovina. Disponível em http://www.ibge.gov.br/home/estatistica/indicad ores/agropecuaria/producaoagropecuaria/abateleite-couro-ovos. Acesso em: 09 mai. 2016. KISSMANN, C.; SCALON, S.P.Q.; SCALON FILHO, H.; RIBEIRO, N. Tratamentos para quebra de dormência, temperaturas e substratos na germinação de AdenantherapavoninaL.

Ciência e Agrotecnologia, Lavras, v. 32, n. 2, p. 668-674, 2008. 
LABOURIAU, L.C. A germinação das sementes. Washington: OEA, 1983. 174p.

LORENZI, H. Plantas daninhas do Brasil: terrestres, aquáticas, parasitas e tóxicas. 3.ed. Nova Odessa: Plantarum, 2000. 112 p.

MAGUIRE, J.D. Speed of germination-aid in relation evaluation for seedling emergence vigor. Crop Science, Madison, v. 2, n. 2, p. 176-177, 1962.

MARCOS FILHO, J. Fisiologia de sementes de plantas cultivadas. Piracicaba: FEALQ, 2005. $495 \mathrm{p}$.

MARTINS, C.; MENDONÇA, C.G.; MARTINS, D.; VELINI, E.D. Superação da dormência de sementes de carrapicho-beiço-deboi. Planta Daninha, Viçosa,v.15, n.1, p.104113, 1997.

MENEZES, N.L.; FRANZIN, S.M.; BORTOLOTTO, R.P. Dormência em sementes de arroz: causas e métodos de superação.

Revista de Ciências Agro-ambientais, Alta Floresta, v.7, n.1, p.35- 44, 2009.

NASSIF, S.M.N.; VIEIRA, I.G.; FERNADES, G.D. Fatores externos (ambientais) que influenciam na germinação de sementes. Informativo Sementes-IPEF, 1998. Disponível em:

http://www.ipef.br/tecsementes/germinacao.asp. Acesso em: 24 ago. 2016.

OLIVEIRA, L.M.; DAVIDE, A.C.; CARVALHO, M.L.M. Avaliação de métodos para quebra da dormência e para a desinfestação de sementes de canafístula

(Peltophorumdubium). Revista Árvore, Viçosa, v.27, n.5, p.597-603, 2003.

PARREIRA, M.C.; CARDOZO, N.P.; GIANCOTTI, P.R.F.; ALVES, P.L.C.A.

Superação de dormência e influência dos fatores ambientais na germinação de sementes de Spermacocelatifolia. Revista Brasileira de Ciências Agrárias, Recife, v.6, n.3, p.427-431, 2011.
REHMAN, S.; HARRIS, P.J.C.; BOURNE, W.F..; WILKIN, J. The effect of sodium chloride on germination and the potassium and calcium contents of Acacia seeds. Seed Science and Technology, Berlin, v.25, n.1, p. 45-57, 1996.

SIQUEIRA-SILVA, A.I.; CORTE, V.B.; PEREIRA, M.D.; CUZZUOL, G.R.F.; LEITE, I.T.A. Efeito da temperatura e de tratamentos pré-germinativos na germinação de sementes de Adenantherapavonina L. Semina: Ciências Agrárias, Londrina, v. 30, n. 4, p. 815-824, 2009.

SILVA, C.E.B.; PARREIRA, M.C.; ALVES, P.L.C.A.; PAVANI, M.C.M.D. Aspectos germinativos de capim-camalote (Rottboelliacochinchinensis). Planta Daninha, Viçosa, v. 27, n. 2, p. 273-281, 2009a.

SILVA, J.L.; GUIMARÃES, S.C.; YAMASHITA, O.M. GerminabilityofChloris barbata (L.) Sw.

seedsundertemperatureandpotassiumnitrateeffec t. Revista de Ciências Agro-ambientais, Alta Floresta, v.7, n.1, p.45- 53, 2009 b.

TOLEDO, F.F.; CHAMMA, H.M.C.P.; NOVEMBRE A.D.L.C. Germinação de sementes de PanicummaximumJacq. prétratadas com ácido sulfúrico. ScientiaAgricola, Curitiba, v.52, n.1, p.20-24, 1995.

VIVIAN, R.; SILVA, A.A.; GIMENES JR., M.; FAGAN, E.B.; RUIZ, S.T.; LABONIA, V. Dormência em sementes de plantas daninhas como mecanismo de sobrevivência: breve revisão. Planta Daninha, Viçosa, v.26, n.2, p.695-706, 2008.

YAMASHITA, O.M.; ALBERGUINI, A.L. Germinação de Vernoniaferruginea em função da quebra de dormência, luminosidade e temperatura. ComunicataScientiae, Bom Jesus, v.2, n.3, p.142-148, 2011. 